Article

\title{
Intravesical Instillation of Azacitidine Suppresses Tumor Formation through TNF-R1 and TRAIL-R2 Signaling in Genotoxic Carcinogen-Induced Bladder Cancer
}

\author{
Shao-Chuan Wang ${ }^{1,2,3}$, Ya-Chuan Chang ${ }^{2}$, Min-You Wu ${ }^{2}$, Chia-Ying Yu ${ }^{2}$, Sung-Lang Chen ${ }^{1,2,3}$ \\ and Wen-Wei Sung $1,2,3, * \mathbb{D}$ \\ 1 Department of Urology, Chung Shan Medical University Hospital, Taichung 40201, Taiwan; \\ cshy764@csh.org.tw (S.-C.W.); cshy650@csh.org.tw (S.-L.C.) \\ 2 School of Medicine, Chung Shan Medical University, Taichung 40201, Taiwan; \\ raptor7037@gmail.com (Y.-C.C.); s0701130@gm.csmu.edu.tw (M.-Y.W.); cyyu2015@gmail.com (C.-Y.Y.) \\ 3 Institute of Medicine, Chung Shan Medical University, Taichung 40201, Taiwan \\ * Correspondence: sungww@csmu.edu.tw or flutewayne@gmail.com; Tel.: +886-4-2473-9595
}

check for updates

Citation: Wang, S.-C.; Chang, Y.-C.; Wu, M.-Y.; Yu, C.-Y.; Chen, S.-L.; Sung, W.-W. Intravesical Instillation of Azacitidine Suppresses Tumor Formation through TNF-R1 and TRAIL-R2 Signaling in Genotoxic Carcinogen-Induced Bladder Cancer. Cancers 2021, 13, 3933. https:// doi.org/10.3390/cancers13163933

Academic Editor: Andrea Morrione

Received: 18 June 2021

Accepted: 2 August 2021

Published: 4 August 2021

Publisher's Note: MDPI stays neutral with regard to jurisdictional claims in published maps and institutional affiliations.

Copyright: (C) 2021 by the authors Licensee MDPI, Basel, Switzerland. This article is an open access article distributed under the terms and conditions of the Creative Commons Attribution (CC BY) license (https:// creativecommons.org/licenses/by/ $4.0 /)$.
Simple Summary: Approximately $70 \%$ of all bladder cancer is diagnosed as non-muscle invasive bladder cancer and can be treated by transurethral resection of the bladder tumor, followed by intravesical instillation chemotherapy. Bacille Calmette-Guérin (BCG) is the first-line agent for intravesical instillation, but its accessibility has been limited for years due to a BCG shortage. Here, our aim was to evaluate the therapeutic role of intravesical instillation of azacitidine, a DNA methyltransferase inhibitor, in bladder cancer. Cell model experiments showed that azacitidine inhibited TNFR1 downstream pathways to downregulate HIF-1 $\alpha$, claspin, and survivin. Concomitant upregulation of the TRAIL R2 pathway by azacitidine ultimately drove the tumor cells to apoptosis. Rats with genotoxic carcinogen-induced bladder cancer showed a significantly reduced in vivo tumor burden after intravesical instillation of azacitidine. These findings might support further clinical trials of azacitidine in bladder cancer.

Abstract: Azacitidine, an inhibitor of DNA methylation, shows therapeutic effects against several malignancies by inducing apoptosis and inhibiting tumor cell proliferation. However, the antitumor effects of azacitidine on urinary bladder urothelial carcinoma (UBUC), especially following intravesical instillation (IVI), are not established. Here, UBUC cell lines were used to analyze the in vitro therapeutic effects of azacitidine. Potential signaling pathways were investigated by antibody arrays and Western blotting. The N-butyl-N-(4-hydroxybutyl) nitrosamine (BBN)-induced rat UBUC model was used for in vivo quantitative analysis of tumor burden. Azacitidine significantly inhibited DNMT expression in UBUC cell lines and reduced cell viability and clonogenic activity, as determined by MTT and colony formation assays, while also inducing significant cytotoxic effects in the form of increased sub-G1 and Annexin V-PI populations (all $p<0.05$ ). Antibody arrays confirmed the in vitro suppression of TNF-R1 and the induction of TRAIL-R2 and their downstream signaling molecules. TNF-R1 suppression reduced claspin and survivin expression, while TRAIL-R2 activation induced cytochrome $C$ and caspase 3 expression. Rats with BBN-induced bladder cancer had a significantly reduced tumor burden and Ki67 index following IVI of azacitidine $(p<0.01)$. Our study provides evidence for a reduction in BBN-induced bladder cancer by IVI of azacitidine through alterations in the TRAIL-R2 and TNF-R1 signaling pathways. These findings might provide new insights for further clinical trials.

Keywords: bladder cancer; azacitidine; intravesical instillation; TNF-R1; TRAIL-R2 


\section{Introduction}

Urinary bladder urothelial carcinoma (UBUC), also known as bladder cancer, is a highly prevalent malignancy worldwide. In 2020, the estimated new cases and deaths were 81,400 and 17,980, respectively, in the United States [1]. Non-muscle invasive bladder cancer (NMIBC) accounts for $70 \%$ of all bladder cancer diagnoses [2], and the management of NMIBC consists mostly of tumor excision via transurethral resection of the bladder tumor (TURBT). Subsequent intravesical instillation (IVI) of chemotherapeutic agents is performed within $24 \mathrm{~h}$ after surgery to eliminate residual cancer cells [3].

IVI therapy directly instills chemotherapy or immunotherapy agents, such as mitomycin C and Bacille Calmette-Guérin (BCG), into the bladder [2]. BCG is the first-line treatment for NMIBC, and it significantly reduces the recurrence of malignancy [4]. BCG has several disadvantages, such as side effects that include a localized inflammatory response and BCG infection; however, a shortage of BCG agent currently limits accessibility to this treatment $[5,6]$. In addition, the tumor recurrence rate remains at about $40 \%$ following chemotherapy instillation [7], indicating that any reduction in the rate of UBUC recurrence will require the exploration of alternative agents or agent combinations for IVI bladder cancer therapy.

The progression of many cancers involves epigenetic abnormalities, such as aberrant DNA or histone methylation, which result in disturbances of gene expression [8,9]. Epigenetic therapy, therefore, plays an essential role in cancer treatment, and the vast majority of epigenetic drugs are histone deacetylase inhibitors (HDACi) and DNA methyltransferase inhibitors (DNMTi) [10]. Ongoing or completed clinical trials of epigenetic drugs for treating bladder malignancy have mainly involved HDACi treatments, with only about $20 \%$ investigating DNMTi efficacy [11]. Similarly, very few studies have explored the intravesical instillation of DNMTi as adjuvant therapy.

One promising DNMTi inhibitor is azacitidine, a type of hypomethylating agent that incorporates into DNA and RNA. It also binds to DNMT1 as an irreversible inhibitor [12], thereby preventing DNA methylation and reactivating tumor suppressor genes [13]. Azacitidine has been used as therapy for myelodysplastic syndromes and it improves outcomes for elderly patients diagnosed with acute myeloid leukemia $[14,15]$. Azacitidine also has therapeutic effects on solid tumors [16]. Currently, most clinical trials have focused on azacitidine as therapy for leukemia, but a few studies have examined the potential of intravenous injection as therapy for urologic malignancies, such as castration-resistant prostate cancer [17].

Azacitidine promotes the expression of tumor suppressor genes and inhibits the proliferation of bladder cancer cell lines, suggesting a potential therapeutic role in UBUC [18]. Azacitidine can also increase the sensitivity of drug-resistant bladder urothelial carcinoma cells to chemotherapy agents [19]. We hypothesized that azacitidine might show an antitumor effect and reduce the tumor recurrence rate in UBUC. The aim of the present study was to examine the anti-tumor effects of azacitidine on UBUC cell lines and to conduct in vivo experiments to assess the feasibility of using IVI of azacitidine as a treatment for UBUC.

\section{Materials and Methods}

\subsection{Cell Culture}

Two UBUC cell lines, T24 and UMUC3, were purchased from The American Type Culture Collection (Manassas, VA, USA) and stored according to the supplier's instructions. Cells were grown in RPMI medium containing $10 \%$ fetal bovine serum, $100 \mathrm{U} / \mathrm{mL}$ penicillin, $100 \mathrm{\mu g} / \mathrm{mL}$ streptomycin, $2 \mathrm{~g} / \mathrm{mL} \mathrm{NaHCO} 3,1 \mathrm{mM}$ sodium pyruvate, and $0.1 \mathrm{mM}$ nonessential amino acids. All cell lines were cultured at $37^{\circ} \mathrm{C}$ and supplied with $5 \% \mathrm{CO}_{2}$.

\subsection{MTT Assays}

The MTT assay was performed to detect the cytotoxicity of azacitidine. Briefly, $2 \times 10^{4}$ cells were seeded into 96-well plates, incubated overnight, and exposed to azacitidine $(0,1$, and 
$10 \mu \mathrm{M})$ for 1 or $24 \mathrm{~h}$ and harvested on the 72 nd hour. MTT solution $(0.5 \mathrm{mg} / \mathrm{mL})$ was added to the wells and incubated for $3 \mathrm{~h}$ at $37^{\circ} \mathrm{C}$. The reaction was ended by the removal of the supernatant, followed by dissolving the formazan product in DMSO. Optical density was measured with an ELISA reader using a $570 \mathrm{~nm}$ filter. Each experiment was performed in triplicate and the cell viability of each group was calculated and analyzed compared to the control.

\subsection{Clonogenic Assay}

T24 ( 250 cells) and UMUC3 (500 cells) treated with azacitidine $(0,1$, and $10 \mu \mathrm{M})$ were seeded into each well of a 6-well plate and incubated for 3 or 10 days. The resulting colonies were fixed with $95 \%$ ethanol for $20 \mathrm{~min}$ and stained with $20 \%$ Giemsa solution for $30 \mathrm{~min}$ at room temperature, as previously described [20]. Each experiment was performed in triplicate and colony counts were calculated for each group.

\subsection{Flow Cytometry Analysis}

Flow cytometry was conducted with a FACSCanto ${ }^{\mathrm{TM}}$ II Cell Analyzer (BD Biosciences, Franklin Lakes, NJ, USA) to determine the cell cycle distribution and percentage of apoptotic cells in each group, as previously described [21]. T24 and UMUC3 cells were seeded in 6-well plates and treated with azacitidine $(0,1$, and $10 \mu \mathrm{M})$ for $72 \mathrm{~h}$. For cell cycle distribution analysis, cells were fixed in pre-chilled $70 \%$ ethanol. The fixed cells were then re-suspended in PBS containing $0.4 \mu \mathrm{g} / \mathrm{mL}$ PI and $0.5 \mathrm{mg} / \mathrm{mL}$ RNase, and analyzed by flow cytometry. Apoptosis was analyzed using an Annexin V-FITC apoptosis detection kit (Strong Biotech Corporation, Taipei, Taiwan) according to the recommended protocol. Cells were re-suspended in binding buffer $(100 \mu \mathrm{L})$, and $2 \mu \mathrm{L}$ Annexin V-FITC and $2 \mu \mathrm{L}$ PI were added. After a $15 \mathrm{~min}$ reaction in the dark, the cell apoptosis rate was evaluated by flow cytometry. Each experiment was performed in triplicate. The percentage of DNA content at different phases of the cell cycle and the cell apoptosis rate were analyzed using FlowJo Software (BD Biosciences, Franklin Lakes, NJ, USA).

\subsection{Hoechst Staining Assay}

Hoechst 33,342 staining was conducted to detect cell apoptosis by cell morphology observation. The UBUC cell lines were seeded into 6-well plates at a density of $2.5 \times 10^{5}$ cells/well and incubated overnight. The cells were then treated with azacitidine $(0,1$, and $10 \mu \mathrm{M})$ for $24 \mathrm{~h}$ and then harvested at $48 \mathrm{~h}$. The cells were thoroughly washed with phosphate buffered saline and stained with Hoechst 33,342 (10 $\mathrm{\mu g} / \mathrm{mL}$, Invitrogen), followed by incubation for $20 \mathrm{~min}$ at $37^{\circ} \mathrm{C}$. Images were captured with a fluorescence microscope (ImageXpress PICO, Molecular Devices, LLC, San Jose, CA, USA, excitation wavelength of $350-390 \mathrm{~nm}$, emission wavelength of $420-480 \mathrm{~nm}$ ) at $20 \times$ magnification. Five different fields were selected, and the condensed nuclei in each field were counted against the total number of nuclei in the field. The percentages of condensed nuclei were plotted for further analysis.

\subsection{Immunoblotting Assays}

T24 and UMUC 3 cells used for immunoblotting were treated with azacitidine $(0,1$, and $10 \mu \mathrm{M} ; 24 \mathrm{~h}$ ) and harvested for further investigation. Proteins were extracted with RIPA lysis buffer containing complete protease inhibitor cocktail tablets (Roche Applied Science, Mannheim, Germany) dissolved in PBS. The cells were lysed by sonication on ice, the extract was centrifuged for $20 \mathrm{~min}$ at $13,800 \times g$ and $4{ }^{\circ} \mathrm{C}$, and the supernatant was stored at $-80^{\circ} \mathrm{C}$. The protein concentration in the supernatant was measured with the Bio-Rad Protein Assay (Bio-Rad Laboratories Inc., Contra Costa, CA, USA). Equal amounts of protein $(15 \mu \mathrm{g})$ were then loaded onto sodium dodecyl sulfate polyacrylamide gel electrophoresis (SDS-PAGE) gels, separated by electrophoresis, and then transferred from the gel to Immobilon ${ }^{\mathrm{TM}}$-P Transfer Membranes (Merck Millipore, Burlington, MA, USA). The membranes were blocked with $5 \%$ non-fat milk and then incubated overnight at $4{ }^{\circ} \mathrm{C}$ with 
the relevant primary antibodies. The membranes were washed with Tris-buffered saline containing Tween 20 (TBST) and then incubated with horseradish-peroxidase-conjugated secondary antibody for $1 \mathrm{~h}$. The membranes were then washed with TBST and reacted with Immobilon ${ }^{\mathrm{TM}}$-Western Chemiluminescent HRP Substrate (Merck Millipore, Burlington, MA, USA). The results were detected with a GE Healthcare ImageQuant LAS4000 instrument, and the band densities were quantified with AlphaEaseFC software using $\beta$-actin for normalization of the results. All antibodies were purchased from ABclonal Science, Inc. (Woburn, MA, USA) and Taiclone Biotech (Tainan, Taiwan).

\subsection{Human Apoptosis Array for Proteome Profiling}

Proteome profiling was conducted using a Human Apoptosis Proteome Profiler ${ }^{\mathrm{TM}}$ array (R\&D Systems, Minneapolis, MN, USA), consisting of a nitrocellulose membrane with duplicate spots of 35 apoptosis-related proteins. T24 and UMUC3 cells were treated with or without azacitidine $(10 \mu \mathrm{M})$ for $24 \mathrm{~h}$, lysed, and $400 \mu \mathrm{g}$ total protein was used for each array following the manufacturer's protocol. The membranes were incubated with horseradish-peroxidase-conjugated antibody, followed by a chemiluminescent detection reagent, and detected with the GE Healthcare ImageQuant LAS4000 instrument (Cytiva, Marlborough, MA, USA). Each experiment was repeated in duplicate, and the integrated density of the spots was quantitated using Image J software (National Institutes of Health, Bethesda, MD, USA).

\subsection{BBN-Induced Bladder Cancer Animal Model (Azacitidine Treatment)}

Female Sprague-Dawley rats weighing between 200 and $230 \mathrm{~g}$ were purchased from the National Laboratory Animal Center. Urinary bladder tumors were induced by administration of $0.05 \%$ N-butyl-N-(4-hydroxybutyl) nitrosamine (BBN, Sunshine Chemical), dissolved in drinking water, for 20 weeks, as described previously [22]. The therapeutic effects of intravesical azacitidine (CAS no.320-67-2, Sigma-Aldrich, St. Louis,, MO, USA) on bladder tumorigenicity in BBN-induced rats were determined by IVI of azacitidine at $1,5,9,13$, and 17 weeks. The IVI protocol was as follows: all rats were anesthetized by intraperitoneal administration of Rompun $(6 \mathrm{mg} / \mathrm{kg})$ and Zoletil $(30 \mathrm{mg} / \mathrm{kg})$. A sterile polyethylene catheter (PE-50) was then inserted into the bladder through the urethra, and all urine was aspirated. The rats in the BBN-induced group underwent IVI with $0.2 \mathrm{~mL}$ azacitidine $(0,10$, or $50 \mu \mathrm{M} ; n=5, n=6, n=6$, respectively; control without $\mathrm{BBN}, n=3)$ under $1 \mathrm{~h}$ of continuous sedation. The non-BBN-induced group of rats underwent IVI with $0.2 \mathrm{~mL}$ PBS under $1 \mathrm{~h}$ of continuous sedation. The rats were euthanized by asphyxiation with $\mathrm{CO}_{2} 20$ weeks after BBN induction. Dissected rat bladders were photographed and used for further analysis.

\subsection{Hematoxylin and Eosin Staining}

Bladder tissues were embedded in paraffin wax, cut into $3 \mu \mathrm{m}$ sections, placed on slides, and stained with hematoxylin/eosin (H\&E) by routine histopathological methods. Briefly, after deparaffinization and rehydration, the tissue sections were immersed in hematoxylin for $10 \mathrm{~min}$ and washed with tap water for $10 \mathrm{~min}$. The slides were then immersed in eosin for $30 \mathrm{~s}$ and dehydrated by immersion in a series of increasing concentrations of alcohol. The sections were then immersed in xylene twice for $10 \mathrm{~min}$ each and coverslipped with mounting medium. The stained specimens were photographed using a TissueFAX Plus system (TissueGnostics, Vienna, Austria) and then analyzed histopathologically.

\subsection{Immunohistochemistry}

Bladder tissues were embedded in paraffin wax and cut into $3 \mu \mathrm{m}$ sections. After deparaffinization and rehydration, antigen retrieval was performed by immersing the sections in citrate buffer ( $\mathrm{pH}$ 6.0) for $30 \mathrm{~min}$ in an autoclave sterilizer and then cooling at room temperature for $10 \mathrm{~min}$. Sections were incubated in $3 \% \mathrm{H}_{2} \mathrm{O}_{2}$ for $10 \mathrm{~min}$, followed by blocking with $10 \%$ goat serum for $1 \mathrm{~h}$. The blocking buffer was removed, and the sections 
were incubated with the primary antibody at a 1:50 dilution (Anti-ki67 antibody \#ab15580, Abcam, Cambridge, England) overnight at $4{ }^{\circ} \mathrm{C}$. Subsequently, the sections were incubated with a biotinylated goat anti-rabbit IgG secondary antibody at a 1:100 dilution, followed by incubation with diaminobenzidine solution (\#ab64238, Abcam) for $1 \mathrm{~min}$. The sections were counterstained with hematoxylin (\#ab220365, Abcam) for $20 \mathrm{~s}$, dehydrated in a series of increasing concentrations of alcohol, immersed in xylene twice for $10 \mathrm{~min}$ each, and coverslipped with mounting medium. The stained specimens were photographed with a TissueFAX Plus system. The Ki-67 index was determined by expressing the numbers of positively stained cells in the bladder transitional epithelium as positive cell number $/ \mathrm{mm}^{2}$, followed by analysis using TissueFAX Plus software.

\subsection{Statistical Analysis}

Statistical analysis was conducted using IBM SPSS software (version 20.0). Data were presented as the mean \pm s.d. Student's $t$-test was used for continuous or discrete data analysis, as described [20,23]. All statistical tests were two-sided (SEM), and values of $p<0.05$ were considered statistically significant $\left({ }^{*} p<0.05 ;{ }^{* *} p<0.01\right.$; $\left.{ }^{* *} p<0.001\right)$.

\section{Results}

3.1. Azacitidine Treatment of the UBUC Cell Lines Suppresses DNMT Expression and Cell Growth

Azacitidine is known to suppress DNMT1 in several malignancies; therefore, we confirmed DNMT suppression by azacitidine in UBUC cells by determining the DNMT protein level by immunoblotting. As shown in Figure 1A, the expression of DNMT1 and DNMT3B in UBUC cells was decreased by treatment with 1 or $10 \mu \mathrm{M}$ azacitidine.

The growth of azacitidine-treated UBUC cells was analyzed to test the cytotoxicity of azacitidine (Figure 1B,C). The MTT assay revealed that the viability of both T24 and UMUC3 cell types decreased after treatment with azacitidine for $1 \mathrm{~h}$ (T24: control vs. $10 \mu \mathrm{M}$, $p=0.001$; UMUC3: control vs. $10 \mu \mathrm{M}, p=0.002$ ) or $24 \mathrm{~h}$ (T24: control vs. $10 \mu \mathrm{M}, p=0.001$; UMUC3: control vs. $10 \mu \mathrm{M}, p=0.001)$. Colony formation assays performed to analyze the clonogenic activity of UBUC cells (Figure 1D-G) revealed a decrease in colony formation (upper panel) by treatment with azacitidine for 3 days (T24: control vs. 1 and $10 \mu \mathrm{M}$, $p=0.91$ and 0.001; UMUC3: control vs. 1 and $10 \mu \mathrm{M}, p=0.005$ and 0.001) and 10 days (T24: control vs. 1 and $10 \mu \mathrm{M}, p=0.004$ and 0.001; UMUC3: control vs. 1 and $10 \mu \mathrm{M}, p=0.001$ and 0.001$)$. The decreases in cell viability and clonogenic activity in response to azacitidine were dose dependent.

\subsection{Azacitidine Induces Apoptosis of UBUC Cell Lines through Claspin and Survivin}

We investigated whether cell growth was inhibited by suppression of cell proliferation or by promotion of cell death by examining the mechanism of cell growth suppression by azacitidine in UBUC cells. As shown in Figure 2A-C, the UBUC cells treated with azacitidine showed sub-G1 accumulation, indicating cell death (T24: control vs. 1 and $10 \mu \mathrm{M}, p=0.0 .45$ and 0.002; UMUC3: control vs. 1 and $10 \mu \mathrm{M}, p=0.001$ and 0.001).

We distinguished between necrotic and apoptotic cells by dual staining with annexin $\mathrm{V}$ and PI and confirmed an apoptosis-inducing effect of azacitidine (Figure 2D-F). The numbers of early and late apoptotic cells increased with azacitidine treatment (T24: control vs. 1 and $10 \mu \mathrm{M}, p=0.024$ and 0.001; UMUC3: control vs. 1 and $10 \mu \mathrm{M}, p=0.001$ and 0.001). Visualization of apoptotic cells by Hoechst 33,342 staining and fluorescence microscopy (Figure 2G-I) revealed increased numbers of apoptotic cells following a $24 \mathrm{~h}$ azacitidine treatment (T24: control vs. 1 and $10 \mu \mathrm{M}, p=0.0001$ and 0.0001; UMUC3: control vs. 1 and $10 \mu \mathrm{M}, p=0.002$ and 0.0001 ). The apoptosis array (Figure 3A,C) identified tumor necrosis factor receptor 1 (TNF-R1) and TNF-related apoptosis-inducing ligand receptor 2 (TRAIL R2) as proteins whose expression was regulated by azacitidine in both UBUC cell lines. Claspin, survivin, and hypoxia-inducible factor 1-alpha (HIF-1 $\alpha$ ) expression was lower in cells treated with $10 \mu \mathrm{M}$ azacitidine than in the control group (Figure 3B,D). 
Investigation of the downstream pathway of TNF-R1 and TRAIL R2 by immunoblotting identified lower expression of a series of proteins involved in the NF- $\kappa B$ pathway (Figure $4 \mathrm{~A}$ ). The reduced expression of claspin, survivin, and HIF- $1 \alpha$ confirmed their roles in the apoptosis pathway (Figure 4B). Evaluation of the expression of proteins in the TRAIL pathway revealed upregulation of the apoptosis markers cytochrome $\mathrm{C}$ and cleaved-caspase 3 following azacitidine treatment (Figure 4C).

(A)

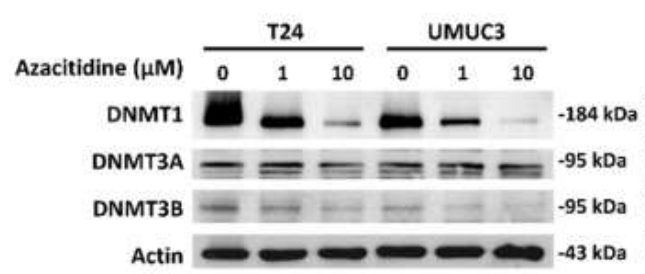

(D)

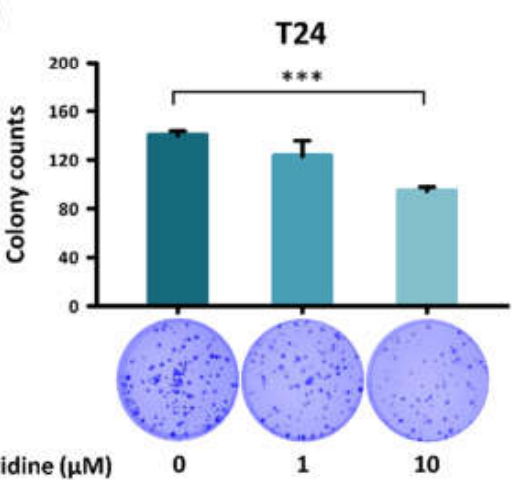

(F)

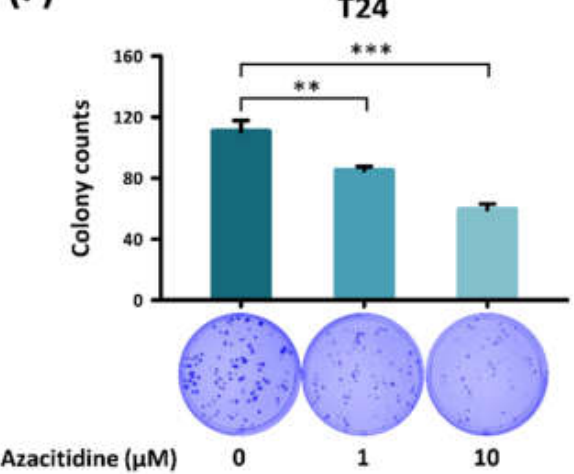

(B)

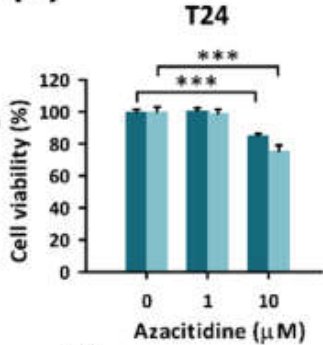

(E)

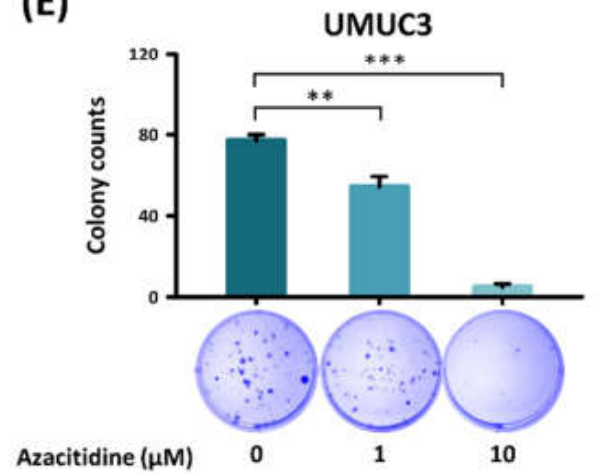

(G)

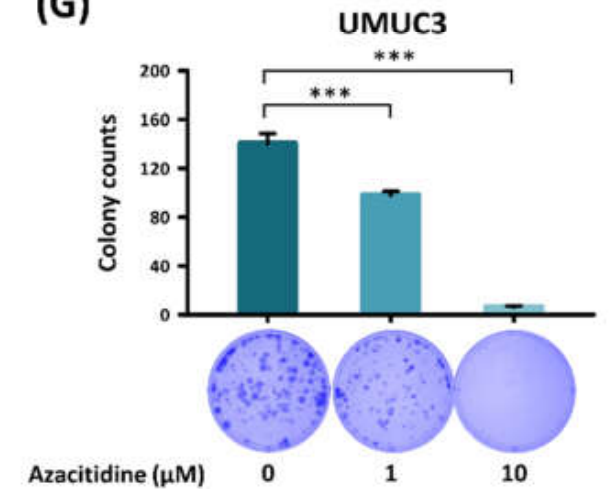

Figure 1. Azacitidine inhibits cell viability and clonogenic activity of UBUC cell lines. (A) Azacitidine inhibited DNMT1 expression. Expression of DNMT family proteins in UBUC cells treated with azacitidine $(0,1$, and $10 \mu \mathrm{M})$ was examined by immunoblotting. (B,C) Azacitidine reduced cell viability of T24 and UMUC3 cells, as determined by the MTT assay. (D-G) Azacitidine inhibited colony formation by T24 and UMUC 3 cells. Colony formation assays were conducted to measure cell growth changes in T24 and UMUC3 cells treated with azacitidine for 3 days $(\mathbf{D}, \mathbf{E})$ or 10 days $(F, G)$ and harvested on the 10th day. Data for colony counts are presented in the upper panel. Data are shown as mean \pm s.d (** $p<0.01$; $\left.{ }^{* * *} p<0.001\right)$. 
(A)

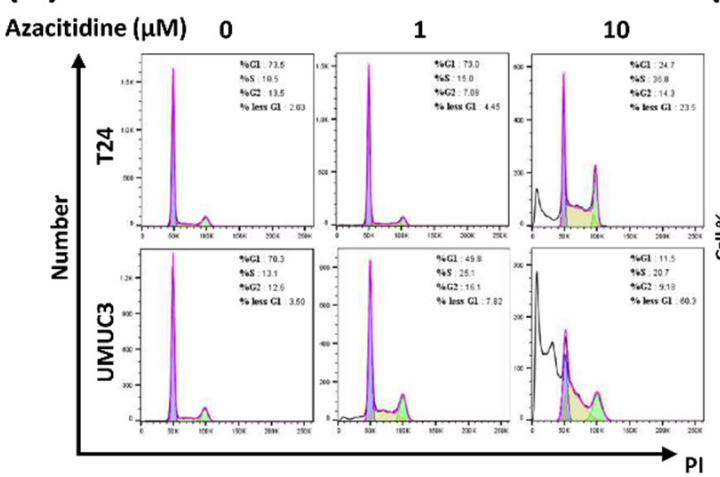

(D)

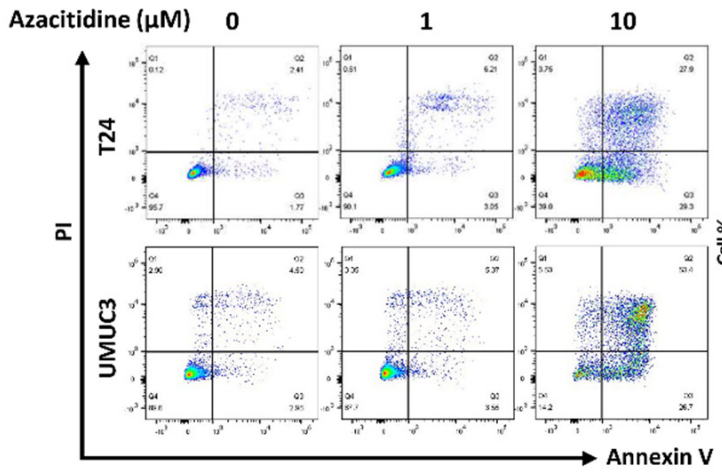

(G)

Azacitidine $(\mu \mathrm{M}) \quad \mathbf{0}$
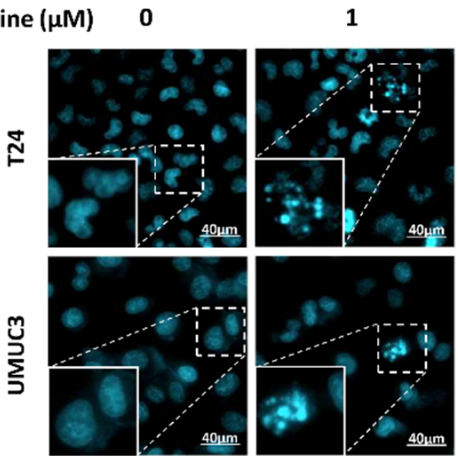

10
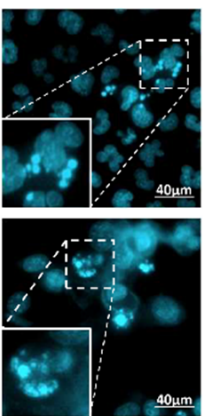

(E)
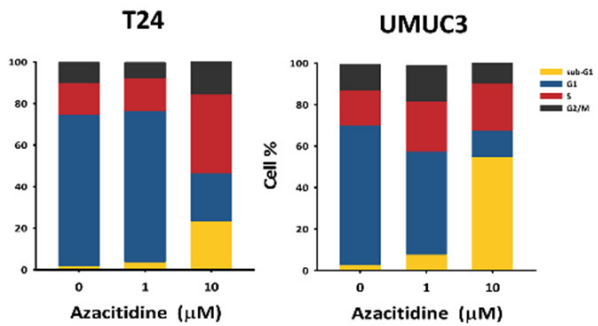

(F)
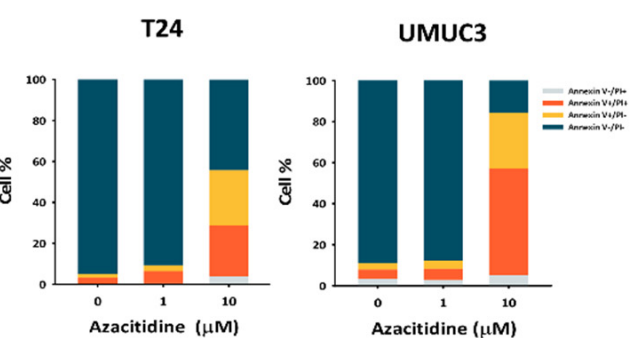

(H)

(I)
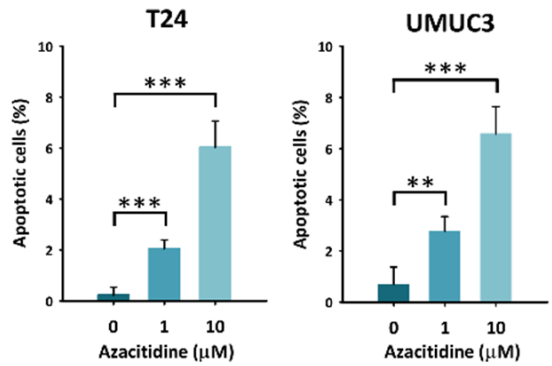

Figure 2. Azacitidine promotes apoptosis of UBUC cell lines. (A) Azacitidine increased the accumulation of UBUC cells in the sub-G1 phase. Cell cycle distributions, analyzed by flow cytometry, are shown for T24 (B) and UMUC3 (C) cells. (D) Azacitidine drove UBUC cell populations to early and late apoptosis, as determined by flow cytometry following dual staining with annexin $\mathrm{V}$ and PI. The proportions of annexin $\mathrm{V}^{+/-}$and $\mathrm{PI}^{+/-} \mathrm{T} 24$ (E) and UMUC3 (F) cells are shown. (G) The numbers of apoptotic UBUC cells increased in response to azacitidine treatment. Cell morphology changes caused by azacitidine were investigated by Hoechst 33,342 staining and viewing at $20 \times$ magnification. (H,I) Columns represent apoptotic cell percentages for T24 and UMUC3 cells. Data are shown as mean \pm s.d. $\left(* * p<0.01 ;{ }^{* * *} p<0.001\right)$. 
(A)

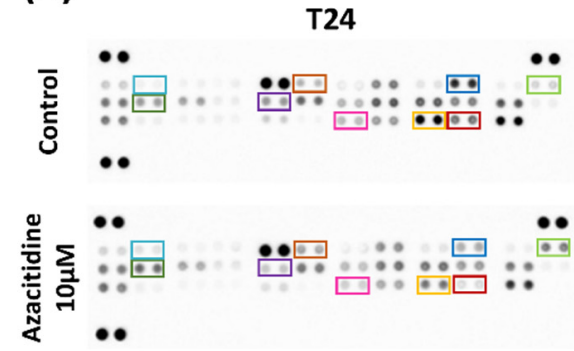

(C)

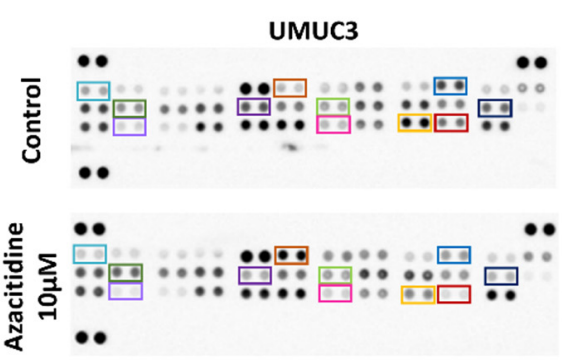

(B)

T24

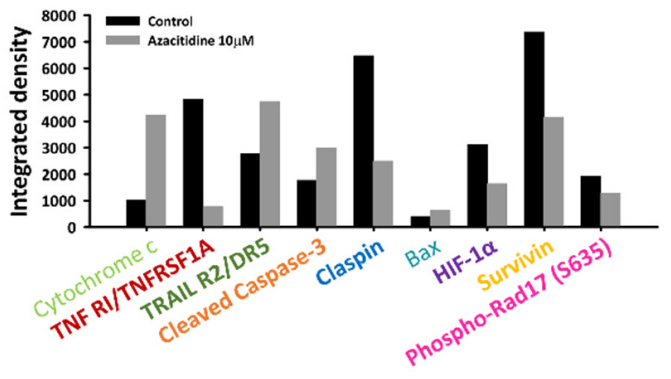

(D)

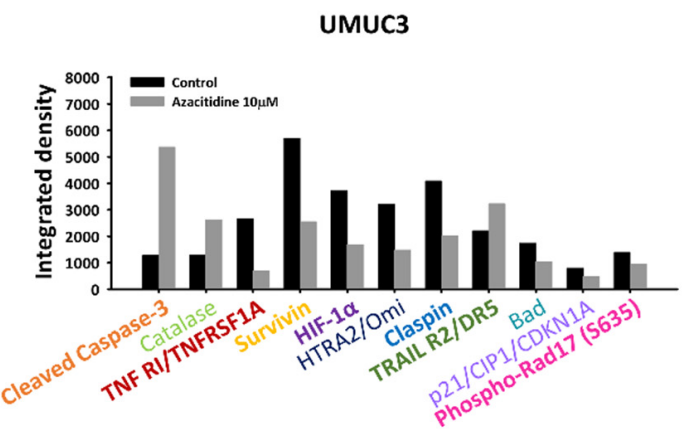

Figure 3. Apoptosis array determination of apoptosis-related protein changes due to azacitidine treatment. T24 (A) and UMUC3 (C) cells treated with azacitidine $(0$ and $10 \mu \mathrm{M})$ for $24 \mathrm{~h}$ were analyzed by apoptosis array. Quantitative analysis showed different changes in apoptotic markers in T24 (B) and UMUC3 (D) cells.

(A)

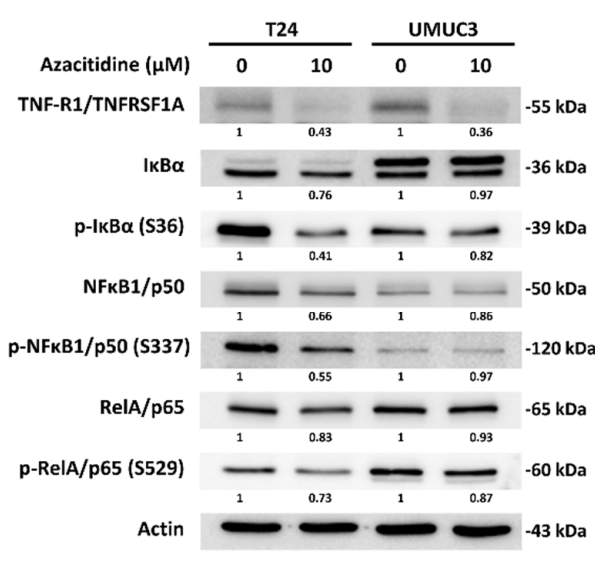

(B)

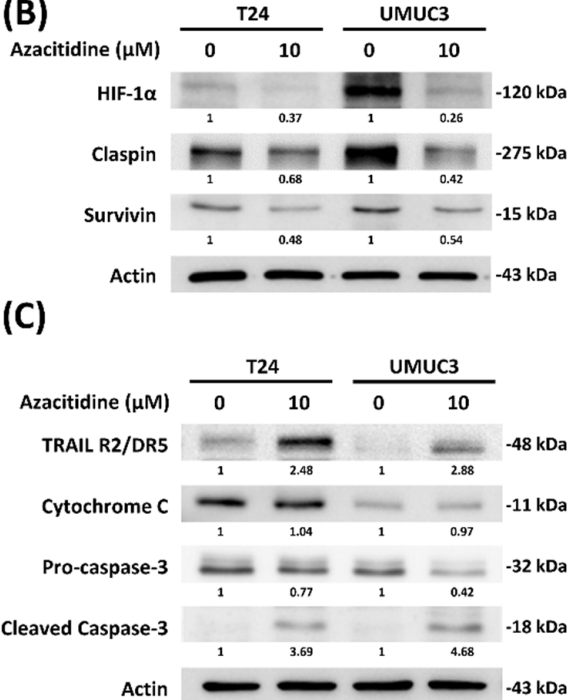

Figure 4. Azacitidine-facilitated apoptosis was associated with downregulation of the NF- $\mathrm{kB}$ pathway and upregulation of the TRAIL R2 pathway. (A) Azacitidine suppressed NF-kB-related protein expression in UBUC cells. (B) HIF-1 $\alpha$, claspin, and survivin expression were inhibited after azacitidine treatment. (C) TRAIL-related protein changes were evaluated after azacitidine treatment.

\subsection{Intravesical Instillation of Azacitidine Suppresses Bladder Cancer Growth in a BBN Rat Model}

A preclinical test was developed to clarify the therapeutic potential of intravesical instillation (IVI) of azacitidine for the treatment of bladder cancer. The timeline and design of the experimental animal model are shown in Figure 5A. The rats were administered $0.05 \%$ 
BBN in their drinking water for 20 weeks to induce bladder cancer and were then given azacitidine by IVI once a month. Tumor lesions in the bladder were decreased by azacitidine treatment (Figure 5B). As shown in Figure 5C,D, immunohistochemistry staining using Ki67 as a marker to detect cell proliferation revealed that azacitidine significantly reduced the numbers of Ki67-positive cells compared to the control group when administered at $10 \mu \mathrm{M}\left(1141 \pm 249\right.$ vs. $760 \pm 128$ cells per $\left.\mathrm{mm}^{2}, p=0.023\right)$ or $50 \mu \mathrm{M}(1141 \pm 249$ vs. $669 \pm 154$ cells per $\mathrm{mm}^{2}, p=0.007$ ) (Figure 5C,D).

(A)

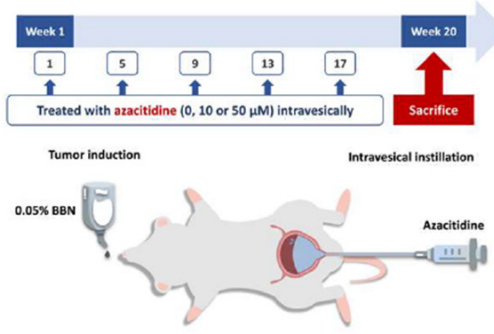

(C)
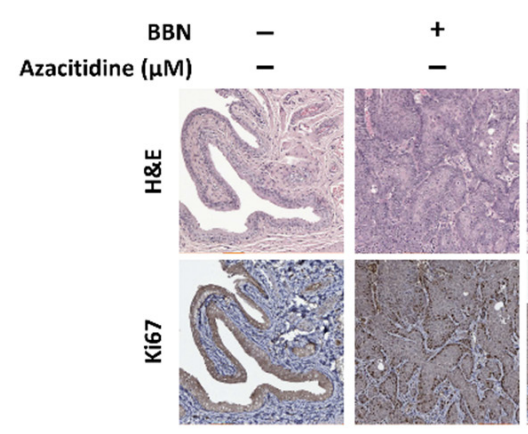

(B)

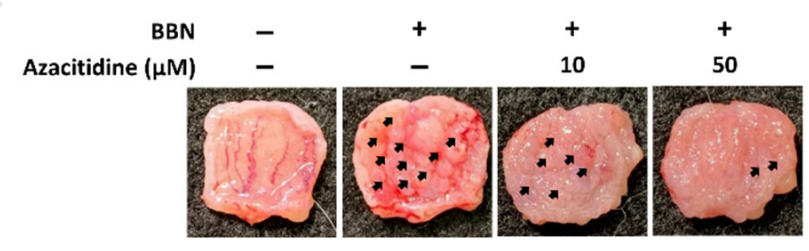

(D)
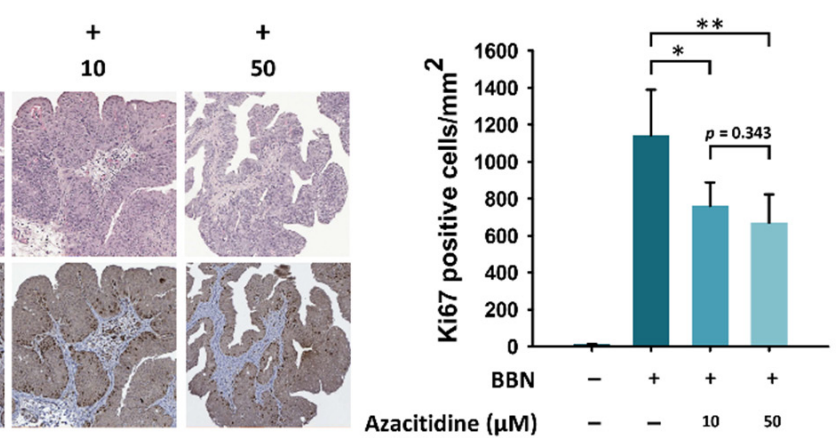

Figure 5. Azacitidine inhibits in vivo tumor growth and lesions in a rat BBN model of bladder cancer. (A) Flow chart of the animal model. Bladder tumors were induced in rats by supplying $0.05 \% \mathrm{BBN}$ in their drinking water. Rats then underwent intravesical instillation of azacitidine (10 or $50 \mu \mathrm{M})$ at 1, 5, 9, 13, and 17 weeks and were sacrificed at week 20. (B) Images of bladder tumor lesions in each group. Azacitidine decreased the tumor lesions in the rat bladder. (C) Azacitidine instillation alleviated cell proliferation in the BBN-induced rat model, as indicated by H\&E staining and immunohistochemistry staining for Ki67. (D) Azacitidine treatment alleviated the proliferation of bladder tumors. Quantitative analysis of Ki67-positive cells of bladder section in each group. Data are the mean \pm s.d. $\left({ }^{*} p<0.05 ;{ }^{* *} p<0.01\right)$.

\section{Discussion}

This study provides the first evidence that the IVI of azacitidine suppresses tumor formation through TNF-R1 and TRAIL R2 signaling in genotoxic carcinogen-induced bladder cancer. UBUC is an obstinate malignancy with a high recurrence rate under current intravesical therapy protocols and it has a poor prognosis. The findings presented here confirm the antiproliferative and apoptosis-activating activities of the DNMT1 inhibitor, azacitidine, in UBUC cell lines and implicated an involvement of the TNFR-NF- $\mathrm{kB}$ and TRAIL pathways in the underlying mechanism. Extension of these in vitro observations to an in vivo rat model confirmed that IVI of azacitidine resulted in a statistically significant reduction in the tumor lesions of the bladder and of the proliferation index marker Ki67. Taken together, our preliminary results validate the potential use of azacitidine as an agent for intravesical therapy of UBUC.

Azacitidine has shown growth-suppressing effects in several tumor types. Kratzsch et al., showed an antiproliferative effect of azacitidine in an in vitro experiment and in a xenograft animal model of glioblastoma [24]. Azacitidine also inhibited the proliferation of diffuse large B-cell lymphoma and germ cell tumor cell lines $[25,26]$. Our work has 
further extended the growth inhibitory effects of azacitidine to include UBUC (Figure 1). Azacitidine might inhibit proliferation through apoptosis or autophagy or by its cytotoxic effects due to incorporation into RNA [27]. Our findings suggest that azacitidine inhibited cell proliferation by inducing apoptosis (Figure 2).

Several studies have indicated that azacitidine drives apoptosis by various pathways. For example, an interferon-induced apoptotic pathway was implicated in epithelial cancers (e.g., ovarian, colorectal, and breast cancers) [28]. Another in vitro study revealed that azacitidine treatment may promote apoptosis in acute myeloid leukemia cells through caspase activation following azacitidine incorporation into RNA [29]. In hepatic cancer cells, azacitidine-induced apoptosis may be associated with expression of the Bcl-2 family proteins [30]. On the Fas-associated death domain, pro-caspase 8 is converted into caspase 8 , which is responsible for cell apoptosis via the activation of caspase 3 [31]. Our work now provides another possibility by showing that azacitidine can promote apoptosis via the TRAIL pathway in UBUC (Figure 4C).

This apoptosis-related signaling pathway is initiated when TRAIL R2 assembles with its TRAIL ligand. Our work is supported by previous observations with detacibine (5-aza-2'deoxycytidine), another DNMT1 inhibitor, which has shown a similar apoptosis-inducing ability via the TRAIL pathway in acute myeloid leukemia and in $\mathrm{HRAS}_{\mathrm{G} 12 \mathrm{~V}}$-transformed cells $[32,33]$. Detacibine is a nucleoside analogue that has lost an oxygen atom at the position 2 carbon atom. In contrast to azacitidine, which incorporates primarily into RNA, detacibine incorporates predominantly into DNA [27].

In addition to the TRAIL pathway mechanism, our findings also implicate a downregulation of the NF- $\mathrm{kB}$ pathway by azacitidine in the UBUC cell lines (Figure 4A). This downregulation ultimately led to suppression of transcription factors p50 and p65 and downregulation of survivin, claspin, and HIF- $1 \alpha$ (Figure 4B). Past research has clarified the role of survivin upregulation by the NF-kB pathway and suppression of apoptosis in bladder cancer [34]. In contrast to our findings, a canine bladder cancer investigation showed no changes in survivin expression following azacitidine treatment [35]. Claspin is an essential DNA-damage checkpoint protein that is degraded by the proteasome, and DNA damage is caused by apoptosis [36]. Previous work by Kenneth et al., showed a critical role for NF-kB modulation of the claspin mRNA level [37]. In their study, IKK $\beta$ reduction was associated with claspin downregulation.

Interestingly, in addition to azacitidine involvement in the pro-apoptosis pathway, other research has found that this drug might drive activation of the pro-survival pathway after long-term drug exposure in myelodysplastic syndrome patients [38]. The increased expression of pro-survival-associated proteins, including the mammalian target of rapamycin (mTOR), PLC $\gamma$, AKT, ERK, and transcription factor STAT3/5, was observed under longterm exposure of azacitidine [38]. These proteins are associated with proliferation and autophagy and might promote cancer cell survival. The cytotoxic activity of azacitidine was augmented when combined with an autophagy inhibitor in samples from myelodysplastic syndrome patients. The JAK-STAT pro-survival pathway is closely linked to cancer cell survival [39], and a recent study suggested that p-STAT, a downstream JAK-STAT pathway protein, bound to the promoter of DNMT1 and triggered tumor progression in glioblastoma [40]. Therefore, the pro-survival pathway might influence the promotor of DNMT1.

Another study has shown drug resistance to azacitidine in the treatment of myelodysplastic syndromes and acute myeloid leukemia [41]. Further investigation revealed that the autophagy inhibitor ROC-325 improved the anti-leukemic action of azacitidine in acute myeloid leukemia cells [42]. Interestingly, detacibine, an analogue of azacitidine, had a similar effect, as it induced autophagy of cancer cells, including UBUC cells $[43,44]$. The autophagy-inducing effect of detacibine was observed in mouse neuronal cell lines, which also showed increased hypoxia tolerance following detacibine treatment. Further investigation revealed that the increased hypoxia-tolerance-dependent autophagy involved the mammalian target of rapamycin (mTOR)-tuberous sclerosis complex 1 (TSC1) pathway. 
In the present study, a BBN rat model was used to unravel the therapeutic role of IVI-administered azacitidine. The observed decrease in Ki67-positive cells demonstrated a possible in vivo inhibition of urothelial tumor proliferation by azacitidine. Previous work has shown a promising therapeutic effect of subcutaneous azacitidine in canine bladder carcinoma [45]. A major limitation of animal models is that a cross section of the bladder does not encompass the entire tumor; that is, some microlesions may be missed. The Ki67 index also has several defects, including different effects on the proliferation of different types of malignancies, and this index may be subjective [46]. Bladder cancer in humans has several risk factors, so one limitation of this model is that the BBN rat model does not mimic the tumorigenic condition of bladder tumors in humans, and oncogene expression in the rat model differs from that in human tumors [47].

IVI of azacitidine has advantages in clinical practice as it can avoid side effects, such as neutropenia and gastrointestinal symptoms, including nausea and vomiting. These were common adverse effects reported following oral administration of azacitidine in a clinical trial studying the therapeutic effect of oral azacitidine on acute myeloid leukemia in elderly patients [48]. Renal toxicity has also been reported, as both proximal and distal tubular damage have been observed in patients receiving systemic azacitidine [49]. In the present study, azacitidine was given by IVI and was expected to show fewer systemic effects than when administered by oral or intravenous routes.

A limitation of our in vitro study was that our cell lines consisted of specific types of UBUC; the T24 and UMUC3 cells are not fully representative of all UBUC types. Furthermore, the mechanism by which azacitidine affects the NF- $\kappa B$ or TRAIL pathways could not be determined without conducting methylation analysis of the entire UBUC genome. The molecular effects of azacitidine identified in vitro were not confirmed in our in vivo investigation, but this could be explained by the long duration (three weeks) between the last azacitidine exposure via IVI and sacrifice. We also did not investigate the potential azacitidine effects on the pro-apoptosis pathway and autophagy previously discussed in many references $[48,49]$. Thus, our inference of the possible pathway might be limited due to a lack of direct evidence.

\section{Conclusions}

Our study highlighted a possible mechanism of azacitidine effects on UBUC. Our work also provided novel therapeutic insights into the benefits of administration of azacitidine by IVI as a therapy for UBUC. Our findings may therefore expand the avenues of bladder cancer therapy.

Author Contributions: Conceptualization, S.-C.W., S.-L.C. and W.-W.S.; data curation, Y.-C.C., M.-Y.W. and C.-Y.Y.; formal analysis, Y.-C.C., C.-Y.Y. and W.-W.S.; methodology, Y.-C.C., C.-Y.Y. and W.-W.S.; supervision, W.-W.S.; writing-original draft, Y.-C.C., M.-Y.W. and C.-Y.Y.; writing-review and editing, S.-C.W., S.-L.C. and W.-W.S. All authors have read and agreed to the published version of the manuscript.

Funding: This work was supported by grants from the Ministry of Science and Technology (MOST 106-2314-B-040-026-MY2 and MOST 108-2314-B-040-014-MY3) and the Chung Shan Medical University Hospital research program (CSH-2018-C-001) of Taiwan.

Institutional Review Board Statement: Not applicable.

Informed Consent Statement: Not applicable.

Data Availability Statement: All data analyzed are included in this article and additional information is available upon request.

Conflicts of Interest: The authors declare no conflict of interest.

\section{References}

1. Siegel, R.L.; Miller, K.D.; Jemal, A. Cancer statistics, 2020. CA Cancer J. Clin. 2020, 70, 7-30. [CrossRef]

2. Lenis, A.T.; Lec, P.M.; Chamie, K.; MSHS, M. Bladder cancer: A review. JAMA 2020, 324, 1980-1991. [CrossRef] 
3. Chang, S.S.; Boorjian, S.A.; Chou, R.; Clark, P.E.; Daneshmand, S.; Konety, B.R.; Pruthi, R.; Quale, D.Z.; Ritch, C.R.; Seigne, J.D.; et al. Diagnosis and treatment of non-muscle invasive bladder cancer: AUA/SUO guideline. J. Urol. 2016, 196, 1021-1029. [CrossRef] [PubMed]

4. Martínez-Piñeiro, J.A.; Martínez-Piñeiro, L. BCG update: Intravesical therapy. Eur. Urol. 1997, 31, 31. [CrossRef] [PubMed]

5. Bandari, J.; Maganty, A.; MacLeod, L.C.; Davies, B.J. Manufacturing and the market: Rationalizing the shortage of Bacillus Calmette-Guérin. Eur. Urol. Focus 2018, 4, 481-484. [CrossRef] [PubMed]

6. Koch, G.E.; Smelser, W.W.; Chang, S.S. Side effects of intravesical BCG and chemotherapy for bladder cancer: What they are and how to manage them. Urology 2021, 149, 11-20. [CrossRef] [PubMed]

7. Gasión, J.P.B.; Cruz, J.F.J. Improving efficacy of intravesical chemotherapy. Eur. Urol. 2006, 50, 225-234. [CrossRef]

8. Michalak, E.; Burr, M.; Bannister, A.J.; Dawson, M.A. The roles of DNA, RNA and histone methylation in ageing and cancer. Nat. Rev. Mol. Cell Biol. 2019, 20, 573-589. [CrossRef]

9. Rhee, I.; Bachman, K.E.; Park, B.H.; Jair, K.-W.; Yen, R.-W.C.; Schuebel, K.E.; Cui, H.; Feinberg, A.; Lengauer, C.; Kinzler, K.W.; et al. DNMT1 and DNMT3b cooperate to silence genes in human cancer cells. Nat. Cell Biol. 2002, 416, 552-556. [CrossRef]

10. Jones, P.A.; Issa, J.-P.; Baylin, P.A.J.S. Targeting the cancer epigenome for therapy. Nat. Rev. Genet. 2016, 17, 630-641. [CrossRef]

11. Faleiro, I.; Leão, R.; Binnie, A.; De Mello, R.A.; Maia, A.-T.; Castelo-Branco, P. Epigenetic therapy in urologic cancers: An update on clinical trials. Oncotarget 2016, 8, 12484-12500. [CrossRef]

12. Issa, J.P.; Kantarjian, H.M.; Kirkpatrick, P. Azacitidine. Nat. Rev. Drug Discov. 2005, 4, 275-276. [CrossRef] [PubMed]

13. Christman, J.K. 5-azacytidine and 5-aza-2'-deoxycytidine as inhibitors of DNA methylation: Mechanistic studies and their implications for cancer therapy. Oncogene 2002, 21, 5483-5495. [CrossRef] [PubMed]

14. Cazzola, M. Myelodysplastic syndromes. Haematologica 2020, 383, 1358-1374.

15. Dombret, H.; Seymour, J.F.; Butrym, A.; Wierzbowska, A.; Selleslag, D.; Jang, J.H.; Kumar, R.; Cavenagh, J.; Schuh, A.C.; Candoni, A.; et al. International phase 3 study of azacitidine vs. conventional care regimens in older patients with newly diagnosed AML with > 30\% blasts. Blood 2015, 126, 291-299. [CrossRef]

16. Cowan, L.A.; Talwar, S.; Yang, A.S. Will DNA methylation inhibitors work in solid tumors? A review of the clinical experience with azacitidine and decitabine in solid tumors. Epigenomics 2010, 2, 71-86. [CrossRef]

17. O'Rourke, C.J.; Knabben, V.; Bolton, E.; Moran, D.; Lynch, T.; Hollywood, D.; Perry, A.S. Manipulating the epigenome for the treatment of urological malignancies. Pharmacol. Ther. 2013, 138, 185-196. [CrossRef]

18. Wang, X.; Chen, E.; Yang, X.; Wang, Y.; Quan, Z.; Wu, X.; Luo, C. 5-azacytidine inhibits the proliferation of bladder cancer cells via reversal of the aberrant hypermethylation of the hepaCAM gene. Oncol. Rep. 2015, 35, 1375-1384. [CrossRef]

19. Ramachandran, K.; Gordian, E.; Singal, R. 5-azacytidine reverses drug resistance in bladder cancer cells. Anticancer Res. 2011, 31, 31.

20. Sung, W.-W.; Wang, Y.-C.; Lin, P.-L.; Cheng, Y.-W.; Chen, C.-Y.; Wu, T.-C.; Lee, H. IL-10 promotes tumor aggressiveness via upregulation of CIP2A transcription in lung adenocarcinoma. Clin. Cancer Res. 2013, 19, 4092-4103. [CrossRef] [PubMed]

21. Sung, W.W.; Wang, Y.C.; Cheng, Y.W.; Lee, M.C.; Yeh, K.T.; Wang, L.; Wang, J.; Chen, C.Y.; Lee, H. A polymorphic -844T/C in FasL promoter predicts survival and relapse in non-small cell lung cancer. Clin. Cancer Res. Off. J. Am. Assoc. Cancer Res. 2011, 17, 5991-5999. [CrossRef]

22. John, B.A.; Said, N. Insights from animal models of bladder cancer: Recent advances, challenges, and opportunities. Oncotarget 2017, 8, 57766-57781. [CrossRef] [PubMed]

23. Chen, S.-L.; Huang, Y.-H.; Wei, T.-Y.; Huang, K.-M.; Ho, S.-H.; Bih, L.-I. Motor and bladder dysfunctions in patients with vertebral fractures at the thoracolumbar junction. Eur. Spine J. 2011, 21, 844-849. [CrossRef] [PubMed]

24. Kratzsch, T.; Kuhn, S.A.; Joedicke, A.; Hanisch, U.K.; Vajkoczy, P.; Hoffmann, J.; Fichtner, I. Treatment with 5-azacitidine delay growth of glioblastoma xenografts: A potential new treatment approach for glioblastomas. J. Cancer Res. Clin. Oncol. 2018, 144, 809-819. [CrossRef]

25. Oing, C.; Verem, I.; Mansour, W.Y.; Bokemeyer, C.; Dyshlovoy, S.; Honecker, F. 5-azacitidine exerts prolonged pro-apoptotic effects and overcomes cisplatin-resistance in non-seminomatous germ cell tumor cells. Int. J. Mol. Sci. 2018, 20, 21. [CrossRef]

26. Wang, W.; Wang, J.; Li, Z.; Zhu, M.; Zhang, Z.; Wang, Y.; Jing, H. Promoter hypermethylation of PTPL1, PTPN6, DAPK, p16 and 5-azacitidine inhibits growth in DLBCL. Oncol. Rep. 2015, 35, 139-146. [CrossRef]

27. Agrawal, K.; Das, V.; Vyas, P.; Hajdúch, M. Nucleosidic DNA demethylating epigenetic drugs-A comprehensive review from discovery to clinic. Pharmacol. Ther. 2018, 188, 45-79. [CrossRef]

28. Li, H.; Chiappinelli, K.B.; Guzzetta, A.A.; Easwaran, H.; Yen, R.-W.C.; Vatapalli, R.; Topper, M.J.; Luo, J.; Connolly, R.M.; Azad, N.S.; et al. Immune regulation by low doses of the DNA methyltransferase inhibitor 5-azacitidine in common human epithelial cancers. Oncotarget 2014, 5, 587-598. [CrossRef]

29. Buchi, F.; Masala, E.; Rossi, A.; Valencia, A.; Spinelli, E.; Sanna, A.; Gozzini, A.; Santini, V. Redistribution of H3K27me3 and acetylated histone $\mathrm{H} 4$ upon exposure to azacitidine and decitabine results in de-repression of the AML1/ETO target geneIL3. Epigenetics 2013, 9, 387-395. [CrossRef]

30. Wang, X.M.; Wang, X.; Li, J.; Evers, B.M. Effects of 5-azacytidine and butyrate on differentiation and apoptosis of hepatic cancer cell lines. Ann. Surg. 1998, 227, 922-931. [CrossRef] [PubMed]

31. von Karstedt, S.; Montinaro, A.; Walczak, H. Exploring the TRAILs less travelled: TRAIL in cancer biology and therapy. Nat. Rev. Cancer 2017, 17, 352-366. [CrossRef] 
32. Lund, P.; Kotova, I.; Kedinger, V.; Khanwalkar, H.; Voltz, E.; Hahn, W.C.; Gronemeyer, H. Transformation-dependent silencing of tumor-selective apoptosis-inducing TRAIL by DNA hypermethylation is antagonized by decitabine. Mol. Cancer Ther. 2011, 10, 1611-1623. [CrossRef] [PubMed]

33. Soncini, M.; Santoro, F.; Gutierrez, A.; Frigè, G.; Romanenghi, M.; Botrugno, O.A.; Pallavicini, I.; Pelicci, P.; Di Croce, L.; Minucci, S. The DNA demethylating agent decitabine activates the TRAIL pathway and induces apoptosis in acute myeloid leukemia. Biochim. Biophys. Acta 2013, 1832, 114-120. [CrossRef] [PubMed]

34. Cui, X.; Shen, D.; Kong, C.; Zhang, Z.; Zeng, Y.; Lin, X.; Liu, X. NF-kB suppresses apoptosis and promotes bladder cancer cell proliferation by upregulating survivin expression in vitro and in vivo. Sci. Rep. 2017, 7, 40723. [CrossRef] [PubMed]

35. Dhawan, D.; Ramos-Vara, J.A.; Hahn, N.M.; Waddell, J.; Olbricht, G.R.; Zheng, R.; Stewart, J.C.; Knapp, D.W. DNMT1: An emerging target in the treatment of invasive urinary bladder cancer. Urol. Oncol. 2013, 31, 1761-1769. [CrossRef] [PubMed]

36. Semple, J.I.; Smits, V.A.; Fernaud, J.R.H.; Mamely, I.; Freire, R. Cleavage and degradation of Claspin during apoptosis by caspases and the proteasome. Cell Death Differ. 2007, 14, 1433-1442. [CrossRef]

37. Kenneth, N.S.; Mudie, S.; Rocha, S. IKK and NF-kappaB-mediated regulation of Claspin impacts on ATR checkpoint function. EMBO J. 2010, 29, 2966-2978. [CrossRef] [PubMed]

38. Romano, A.; Giallongo, C.; La Cava, P.; Parrinello, N.L.; Chiechi, A.; Vetro, C.; Tibullo, D.; Di Raimondo, F.; Liotta, L.A.; Espina, V.; et al. Proteomic analysis reveals autophagy as pro-survival pathway elicited by long-term exposure with 5-azacitidine in high-risk myelodysplasia. Front. Pharmacol. 2017, 8, 204. [CrossRef]

39. Owen, K.L.; Brockwell, N.K.; Parker, B.S. JAK-STAT signaling: A double-edged sword of immune regulation and cancer progression. Cancers 2019, 11, 2002. [CrossRef] [PubMed]

40. Yu, H.; Zhang, S.; Ibrahim, A.N.; Wang, J.; Deng, Z.; Wang, M. RCC2 promotes proliferation and radio-resistance in glioblastoma via activating transcription of DNMT1. Biochem. Biophys. Res. Commun. 2019, 516, 999-1006. [CrossRef]

41. Robert, G.; Auberger, P. Azacitidine resistance caused by LAMP2 deficiency: A therapeutic window for the use of autophagy inhibitors in MDS/AML patients? Autophagy 2019, 15, 927-929. [CrossRef] [PubMed]

42. Nawrocki, S.T.; Han, Y.; Visconte, V.; Przychodzen, B.; Espitia, C.M.; Phillips, J.; Anwer, F.; Advani, A.; Carraway, H.E.; Kelly, K.R.; et al. The novel autophagy inhibitor ROC-325 augments the antileukemic activity of azacitidine. Leukemia 2019, 33, $2971-2974$. [CrossRef] [PubMed]

43. Schnekenburger, M.; Grandjenette, C.; Ghelfi, J.; Karius, T.; Foliguet, B.; Dicato, M.; Diederich, M. Sustained exposure to the DNA demethylating agent, 2'-deoxy-5-azacytidine, leads to apoptotic cell death in chronic myeloid leukemia by promoting differentiation, senescence, and autophagy. Biochem. Pharmacol. 2011, 81, 364-378. [CrossRef]

44. Zhang, H.H.; Huang, B.; Cao, Y.H.; Li, Q.; Xu, H.F. Role of 5-aza-CdR in mitomycin-C chemosensitivity of T24 bladder cancer cells. Oncol. Lett. 2017, 14, 5652-5656. [CrossRef] [PubMed]

45. Hahn, N.M.; Bonney, P.L.; Dhawan, D.; Jones, D.R.; Balch, C.; Guo, Z.; Hartman-Frey, C.; Fang, F.; Parker, H.G.; Kwon, E.M.; et al. Subcutaneous 5-azacitidine treatment of naturally occurring canine urothelial carcinoma: A novel epigenetic approach to human urothelial carcinoma drug development. J. Urol. 2012, 187, 302-309. [CrossRef] [PubMed]

46. Miller, I.; Min, M.; Yang, C.; Tian, C.; Gookin, S.; Carter, D.; Spencer, S.L. Ki67 is a graded rather than a binary marker of proliferation versus quiescence. Cell Rep. 2018, 24, 1105-1112.e5. [CrossRef]

47. Fantini, D.; Glaser, A.; Rimar, K.J.; Wang, Y.; Schipma, M.; Varghese, N.; Rademaker, A.; Behdad, A.; Yellapa, A.; Yu, Y.; et al. A carcinogen-induced mouse model recapitulates the molecular alterations of human muscle invasive bladder cancer. Oncogene 2018, 37, 1911-1925. [CrossRef]

48. Wei, A.H.; Döhner, H.; Pocock, C.; Montesinos, P.; Afanasyev, B.; Dombret, H.; Ravandi, F.; Sayar, H.; Jang, J.-H.; Porkka, K.; et al. Oral azacitidine maintenance therapy for acute myeloid leukemia in first remission. N. Engl. J. Med. 2020, 383, 2526-2537. [CrossRef]

49. Peterson, B.A.; Collins, A.J.; Vogelzang, N.J.; Bloomfield, C.D. 5-azacytidine and renal tubular dysfunction. Blood 1981, 57, 182-185. [CrossRef] [PubMed] 